\title{
PEDAGOGÍA Y NACIONALISMO EN LA ARGENTINA: LO INTERNACIONAL Y LO LOCAL EN LA INSTITUCIONALIZACIÓN DE LA ENSEÑANZA DE LA ARQUEOLOGÍA
}

\author{
PEDAGOGY AND NATIONALISM IN ARGENTINA: THE LOCAL AND THE \\ INTERNATIONAL IN THE INSTITUTIONALIZATION OF THE TEACHING \\ OF ARCHAEOLOGY
}

\author{
SUSANA V. GARCÍA $(*)$ \\ IRINA PODGORNY $(*)$
}

\begin{abstract}
"En nuestros días, el cultivo de las ciencias no está ya reducido a un país privilegiado, ni siquiera a Europa, es internacional. Todos los problemas, los mismos problemas, son simultáneamente estudiados por doquiera" (Langlois y Seignobos, 1913: 56-57).

"El culto argentino del color local es un reciente culto europeo que los nacionalistas deberían rechazar por foráneo" (Borges, 1990: 270).

"Cada Profesión tiene sus fetichismos; y el material de enseñanza constituye el fetiche de primera magnitud para el cuerpo docente" (Barnés, Secretario del Museo Pedagógico Nacional de Madrid, 1917: 199).
\end{abstract}

\section{RESUMEN}

En este trabajo nos proponemos analizar el papel de los museos arqueológicos y antropológicos, las excursiones y la reproducción de los objetos arqueológicos en la enseñanza de la historia en laArgentina finisecular. Asimismo, se presentan aquí algunas de las ideas que, al respecto, circulaban en España y en otros países europeos y los intercambios entre las instituciones sudamericanas y españolas.

\begin{abstract}
In this paper we analyse the role of archaeological and anthropological museums, fieldtrips and replication of archaeological objects within the framework of the teaching of history in Argentina at the turn of the century. We also present some of the current ideas on the teaching of archaeology in Spain and other European countries, and the exchanges established with South America.
\end{abstract}

(*) Dpto. Científico de Arqueología y Archivo Histórico de la Facultad de Ciencias Naturales y Museo de la Universidad Nacional de La Plata. Paseo del Bosque s/n, 1900 La Plata, Argentina. Correo electrónico: archivo@museo.fcnym.unlp.edu.ar; podgorny@mail.retina.ar

Este artículo fue remitido en su versión final el 12-IX-2001.
Palabras clave: Historia de la Arqueología. Argentina. Europa. Museos. Universidades. Educación. Nacionalismo.

Key words: History of Archaeology. Argentine. Europe. Museums. Universities. Education. Nationalism.

\section{INTRODUCCIÓN}

La consolidación de los sistemas educativos estatales como una de las bases del orden liberalburgués es un fenómeno que caracteriza, junto con las transformaciones políticas y económicas, las últimas décadas del siglo XIX europeo y americano (Gellner, 1988; Hobsbawm, 1969, 1990). La educación, en ese sentido, aparece ligada tanto a la posibilidad de contribuir al desarrollo de las industrias nacionales y locales como a la de salvaguardar y fortalecer las incipientes nacionalidades a través de la enseñanza de las "tradiciones", la historia, la lengua y la geografía. Esto conformaba el "cemento" que, introducido entre las poblaciones gobernables, daría cohesión a la Nación (Hobsbawm y Ranger, 1983). 
La emergencia de una "enseñanza nacional" estructurada sobre contenidos locales podría llegar a oscurecer que ello formó parte de la mundialización de la "necesidad" tanto de educación como del desarrollo de la ciencia y de la industria (Lafuente $e t$ alii, 1993).Adoptando una perspectiva más amplia, aquello que parece una reivindicación de lo regional o nacional debe entenderse en el marco de la expansión internacional de determinadas ideas y prácticas (entre las que se incluye la de lo local), siendo la articulación con los procesos locales lo que crea, efectivamente, una particularidad. A este respecto es importante destacar que el desarrollo de la comunicación marítima y postal posibilitó la rápida circulación de los libros, folletos, catálogos y revistas que contenían las "innovaciones" que se daban en la educación y en la ciencia de todos los países en juego. Las lecturas de dichas propuestas establecieron la idea de la "adaptación" de las mismas -opuesta a la de imitación- a las características locales. Asimismo, como una práctica ampliamente difundida se contaba el envío de los profesores en misiones oficiales para que in situ se relevaran-y a posteriori se compararan- las distintas metodologías y sistemas de enseñanza. Recordemos, además, que la enseñanza de la historia en el grado de enseñanza primario de las escuelas europeas fue incorporada con carácter obligatorio en las últimas décadas del siglo XIX y que, hasta 1894, era facultativa en Dinamarca, Grecia, Suecia y Baviera (Altamira, 1894: 2). Por otro lado, la enseñanza de la arqueología prehistórica había sido incorporada a la enseñanza básica de Suiza en una fecha tan temprana como mediados de la década de 1860 , para la admiración de Gabriel de Mortillet (1867: 1) que veía en ello un ejemplo a seguir en Francia y en todos los países que se considerasen portadores del estandarte del progreso (Podgorny, 2000a).

Para los autores de la época, la enseñanza de la historia era un problema técnico (de los profesionales) y también de los pedagogos. Para ambos surgía un problema metodológico fundamental cual era la sujeción al libro de texto y a la autoridad del relator de la historia. Una metodología activa, basada en la crítica del documento y en la observación del monumento, parecía esbozarse como ideal. En este artículo nos proponemos analizar las iniciativas relativas a la enseñanza de la historia a través de los objetos arqueológicos, la visita a museos y las excursiones tal como eran presentadas en los trabajos europeos de fines de siglo XIX y principios del XX.Asimismo, aceptando la expansión internacio- nal de estas ideas y tomando el caso argentino, nos proponemos comparar las distintas propuestas que se generaron en el contexto de la educación oficial. Tomaremos como referencia las publicaciones e ideas que se promovieron desde la Universidad y el Museo de La Plata (Lám. I), la Facultad de Filosofía y Letras y el Museo Etnográfico de la Universidad de Buenos Aires, aquellas relacionadas con las visitas y las lecturas de la obra de RafaelAltamira (1), del movimiento de extensión universitaria de la Universidad de Oviedo y las asociaciones internacionales de enseñanza. Ligado a ello aparece el problema de la educación y de la profesionalización de la práctica arqueológica. Recordemos que en esos años aparecen las primeras cátedras universitarias de arqueología en laArgentina, contexto pedagógico en el que se consolida la práctica de la arqueología de campo y en el que esta disciplina aparece como proveedora de un nexo entre el suelo, la patria y sus habitantes. Esto también coincide con cierta difusión de la idea que la decoración y los objetos arqueológicos eran elementos para impulsar el desarrollo de un arte americano.

Quizás sería oportuno recordar aquí que a principios de siglo XX en las instituciones científicas de la Argentina la palabra arqueología designaba el estudio de las antigüedades prehistóricas y protohistóricas. Es decir, aquello relacionado con el pasado de "los primitivos habitantes de la República Argentina". Por otro lado, las primeras síntesis clasificatorias de los aborígenes argentinos del pasado y del presente datan también de la primera década del siglo pasado (Podgorny, 2001). En ellas se utilizaba la denominación "tiempos pre y protohistóricos", clasificados en Período Paleolítico y Neolítico, refiriéndose este último a las "agrupaciones" aborígenes que encontraron los españoles. Sin embargo, aquellos pueblos históricos y sedentarios del Noroeste argentino sirven para constituir la "Edad del Bronce". Como mencionaremos en el artículo, las clasificaciones arqueológicas basadas en períodos empezaron a ser reemplazadas por otras sustentadas en criterios geoétnicos en la década que se inicia en 1910 (cf. Podgorny, 1999a). Hacia 1916, se hablaba también de un período precolombiano de la historia de América.

(1) El viaje de Rafael Altamira por América ha sido mencionado en numerosas obras. Como fuente primaria es interesante consultar el informe de Altamira (1911) sobre las actividades que realizó en los diferentes países visitados. En cuanto a la bibliografía secundaria se puede señalar, entre otros: Melón (1988) y los trabajos vinculados a la difusión del krausismo por Latinoamérica (AA.VV., 1989)

T. P., 58, n. $^{\circ} 2,2001$ 


\section{LA INSTITUCIONALIZACIÓN DE LA ENSEÑANZA DE LA ARQUEOLOGÍA}

El énfasis puesto en los últimos años en estudios sobre la enseñanza de la arqueología y la relación entre su institucionalización y el surgimiento de las naciones modernas (Kohl y Fawcett, 1995; Díaz Andreu y Champion, 1996; Mora y Díaz Andreu, 1997) permite iniciar una tarea de comparación entre estos procesos que, desarticulados, pueden verse como específicos. Por otro lado no queremos dejar de señalar que el acento en la función "nacionalista" de la arqueología y de la historia puede enmascarar el lugar de estas disciplinas en un universo, en principio diferente, como es el desarrollo de las industrias del turismo y del ocio de las clases medias de fines del siglo XIX.

En Europa, el fin de siglo XIX es testigo de la institucionalización y profesionalización de la arqueología prehistórica, de la enseñanza de las ciencias y de la consolidación de las universidades como los centros de la práctica científica (Trigger, 1989). En efecto, a lo largo del siglo XX esta última institución integraría la docencia y la investigación en el proceso de formación de los científicos. De esta manera, las universidades concentraron las funciones que, hasta entonces, se adjudicaban diferencialmente los museos, las sociedades eruditas, las academias científicas y las escuelas de educación superior (Pyenson y Sheets-Pyenson, 1999). Más allá de las diferencias, los modelos de universidad francés, alemán e inglés se consolidaron sobre la idea de ser ellas los centros rectores de la vida científica nacional (Ringer, 1995). Este proceso fue paralelo al relativo eclipse de las sociedades eruditas que proliferaron en los siglos XVIII y XIX tanto en las metrópolis como en las provincias (Morrell y Thackray, 1981; Inskter y Morrell, 1993; Mora y Díaz Andreu, 1997). Las sociedades científicas, recordemos, podían coadyuvar a la tarea propuesta desde las instituciones nacionales, pero, sobre todas las cosas, consistían en asociaciones privadas y en la reunión de individuos, profesionales y amateurs que, en base al tiempo libre y a los propios recursos, propendían al desarrollo de la ciencia.

Frente al grado creciente de profesionalización, algunas asociaciones fueron objeto de críticas de parte de los científicos pero también del intento de cooptación por parte del Estado (Schnapp, 1996). En ese marco, los miembros de las sociedades no capitalinas postularon su papel en la reconstitución de la individualidad histórica de las provincias al mismo tiempo que se presentaban como un eslabón intermediario en la formación histórica nacional. Así, en España y en Francia, por ejemplo, se planteaba que, a fin de evitar la destrucción de los sitios arqueológicos, era necesaria una tarea de vulgarización de los conocimientos arqueológicos en la que las sociedades de provincia constituían el eslabón necesario entre "la ciencia" y el público. Con el objetivo de, por ejemplo, "sauvegarder la physionomie phisique et morale de la terre française" (Babelon, 1910: 324) se proponía tres modalidades de popularización: a) publicaciones populares ilustradas, b) conferencias con proyecciones y c) los paseos arqueológicos y visitas a museos. Estas maneras de promover el estudio y la observación de ruinas arqueológicas se instituyó en varios países europeos (Cortadella Morral, 1997; Rueda Muñoz, 1997). En otros sitios, como en Cataluña, los objetivos de las soćiedades de aficionados se relacionan con un "renacimiento de la cultura y del paisaje local" y, en este marco, las ruinas arqueológicas y los museos se toman como sitios que condensan y presentan los rasgos de la historia regional (Cortadella Morral, 1997). Es de destacar que estas sociedades, formaban parte de la cultura científica de la época, ya que sus miembros se constituyeron en corresponsales y formaron parte de las redes de intercambio e información establecidas con las instituciones y academias centrales. Así, por ejemplo, en España, la RealAcademia de Historia publicaba las noticias enviadas desde todos los rincones de la Península Ibérica por una multitud de informantes y estudiosos locales, quienes en varias ocasiones mandaban junto con las noticias de los descubrimientos, piezas arqueológicas, dibujos, fotografías y calcos (Gómez-Pantoja, 1997). Por otra parte, las diferencias entre los inicios del principio y el fin del siglo XIX, muestran el pasaje de lo que era una práctica de un grupo de aristócratas que dedicaba sus horas de ocio a la contemplación de la naturaleza a lo que constituye una actividad de las clases medias.

En la Argentina, las primeras iniciativas de excavaciones arqueológicas datan de la década de 1870 y provinieron de iniciativas particulares que buscaron su aval en las sociedades o instituciones nacionales y provinciales. En esa época las investigaciones arqueológicas habían propendido a la formación de colecciones particulares y, desde la década de 1890, de colecciones para los Museos de La Plata y Nacional de Buenos Aires (Podgorny, 
2000d) (2). Estos dos museos respondían a un modelo de representar el conjunto de la naturaleza argentina y su acervo incluía desde colecciones geológicas hasta los restos del "indio últimamente vencido" (Moreno, 1890:46) (3). Por otro lado, estos centros, independientes de otras instituciones y subordinados directamente uno al Ministerio de Obras Públicas de la Provincia de BuenosAires, el otro al Ministerio de Instrucción Pública de la Nación, se definían como aquellos lugares desde donde se exploraría el territorio nacional. Las primeras cátedras universitarias de arqueología proceden de los años cercanos al inicio del siglo XX (Fernández, 1979-80: 53). En la Universidad de Buenos Aires, el plan de estudios de 1899 de la Facultad de Filosofía y Letras (creada en 1896) estableció la cátedra de Arqueología Americana entre las asignaturas de Quinto año con Samuel Lafone Quevedo como profesor. En la Universidad Nacional de La Plata, establecida en 1906 a partir de la incorporación de varias instituciones educativas y científicas como el Museo de la Plata, transformado en Instituto de investigaciones y Facultad de Ciencias Naturales, se ofreció Arqueología Argentina como materia complementaria para la especialización en antropología y en la de etnología en los planes de estudios de 1909 y 1914, a cargo de Luis María Torres (4).

(2) Los estudios de Florentino Ameghino (1880) en la zona del Plata pretendían resolver el problema de la antigüedad del hombre en América. Los de Juan Bautista Ambrosetti (1902, 1905) sobre la Puna y el Noroeste argentino, basados en colecciones y datos recopilados por otros, intentaban formar un catálogo de las antigüedades $\mathrm{y}$, por otro lado, estudiar la conformación de las poblaciones prehistóricas de esta zona (Podgorny, 1997; 2000d).

(3) En el último tercio del siglo XIX el Gobierno Argentino promueve la incorporación de extensos territorios indígenas al Estado Nacional. Esta anexión de tierras se llevó a cabo a través de una serie de campañas militares que en el relato histórico nacional se ha denomino como "conquista del desierto". Al crearse el Museo de la Plata en 1884 se recibieron en donación colecciones particulares de cráneos y esqueletos indígenas recogidos durante esas campañas y otros viajes de exploración, los cuales fueron exhibidos en una sala de antropología comparada. Al mismo tiempo la institución albergó a algunos caciques y parte de su grupo familiar que permanecían prisioneros (Podgorny y Politis, 1990-92).

(4) En 1909 se aprobó un programa para Arqueología Argentina y se dictó un curso cuatrimestral a un solo alumno, Teodoro de Urquiza, el único que en esa época había seleccionado la especialidad de antropología dentro de la carrera del doctorado en ciencias naturales. Esta materia volvió a ser incluida en los planes de estudio de fines de la década de 1920 como materia especial para los estudiantes del doctorado en ciencias naturales que deseaban especializarse en antropología. Aparentemente durante esa época esta materia no tuvo estudiantes. Ni las memorias ni las actas de exámenes registran el dictado de esta materia (Archivo Histórico Facultad de Ciencias Naturales y Museo -AHCN-: Actas de exámenes 1909-1935).

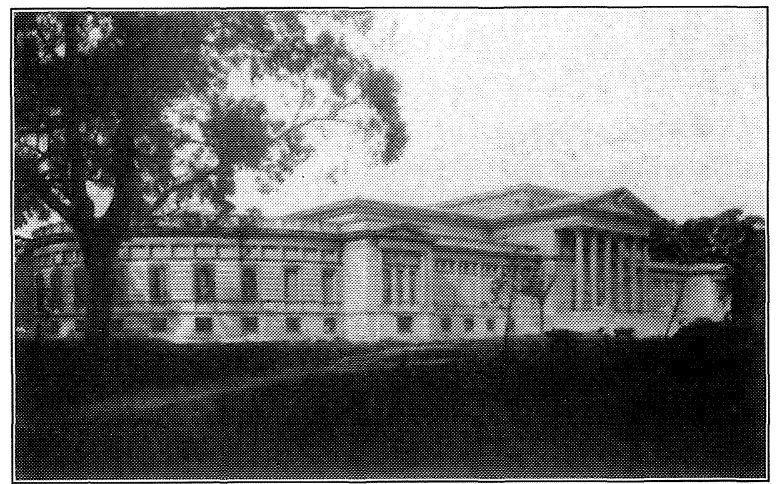

Lám. I. Edificio del Museo de La Plata desde el parque del Jardín Zoológico.

El Museo Etnográfico de la Facultad de Filosofía y Letras de la Universidad de BuenosAires fue el primero en separar las colecciones etnográficas/ antropológicas de las de historia e historia natural y en consolidarse como centro formador de universitarios (5) (Podgorny, 2000d). Su primer director desde 1904 hasta 1917, fue Juan Bautista Ambrosetti quien, previamente, había sido jefe de la Sección deArqueología del Museo Nacional (19021904). El Museo organizó expediciones arqueológicas al Noroeste argentino, con recursos limitados y con la ayuda de los mecenas de la política (6). En principio, el personal de las expediciones se componía de los alumnos y profesores de la Facultad que solicitaran tomar parte en ellas (Ambrosetti, 1912). Esto respondía a la realización por parte de la Facultad de Filosofía y Letras del objetivo de dar una forma práctica a la enseñanza de la arqueología americana y del"ideal universitario, dentro de la parte que le corresponde, de fomentar la alta cultura no profesional" (Anónimo, 1910: 259).

(5) Las secciones del Museo eran las siguientes: Arqueología (con una parte especial de Arqueología calchaquí), Etnografía, Antropología. Había también una Sala de Monumentos Americanos, un Laboratorio y un aula integrada a las salas.

(6) La expedición a la Pampa Grande en la provincia de Salta, primera expedición del Museo Etnográfico, se realizó con el concurso de Indalecio Gómez, por entonces embajador en Alemania y académico honorario de Filosofía y Letras. Indalecio Gómez, que había donado sus colecciones al Museo, invitó a Ambrosetti a investigar en su establecimiento de campo, gracias a lo cual "se pudo realizar la expedición con fondos reducidos, pues él facilitó los elementos necesarios para el mejor éxito de nuestros trabajos" (Ambrosetti, 1906). La expedición solicitó los pasajes necesarios al Poder Ejecutivo y se destinaron 1000 pesos para gastos de fotografía, manutención de campo, y de peones y arrieros. En esta primera expedición participaron dos alumnos del curso de Arqueología (Dres. Leopoldo Maupas y Francisco Cervini) y Carlos Octavio Bunge, profesor de la Facultad. Bunge publicaría noticias sobre las antigüedades calchaquíes en Nuestra patria, libro de lectura para la educación nacional en las escuelas primarias y normales (Podgorny, 2000d). 


\section{LA RESTAURACION NACIONALISTA}

En laArgentina de 1909, Ricardo Rojas publicaba su informe sobre la enseñanza de la historia en los países europeos. Este resultaba de la misión encomendada por el Ministro de Justicia e Instrucción Pública de la Nación como un asunto ligado a "los más vitales intereses de nuestra nacionalidad" (Rojas, 1909: 9). En este informe, los museos, la protección del patrimonio arqueológico, el uso de réplicas de los objetos del pasado (incluyendo en este apartado el arte y la cultura material de la antigüedad) aparecía como algo consolidado y a emular siguiendo el modelo de algunos países delViejo Mundo, en particular Alemania, Inglaterra y Francia. Asimismo, la Universidad de La Plata había encomendado a Ernesto Quesada otra misión análoga, extensiva a todas las naciones europeas. A diferencia de Rojas, Quesada observó y se concentró en las clases de Historia y la enseñanza en las universidades alemanas, impulsando el desarrollo de seminarios para la enseñanza de la Historia. Quesada (1910) subrayaba que estos debían basarse en el modelo alemán y no en los de la Universidad de Oviedo, que, según este autor, tan de moda estaba por esa época a pesar de ser sólo una mera “universidad provincial". Sin embargo, más allá de las advertencias de Quesada, la Universidad de La Plata convocó a un profesor de la universidad asturiana para la organización de la sección (7).

En efecto, en 1909 en el marco del programa de cooperación interuniversitaria que fomentaba las universidades de Oviedo y La Plata, RafaelAltamira fue invitado para dictar un curso sobre metodología en la historia, "iniciando la vinculación intelectual de los países americanos con los grandes pensadores de Europa y ofrece la oportunidad á la República para abrir rumbos en el campo aun poco explorado de las ciencias históricas» (8). Su curso en La Plata se dividió en tres: a) conferencias para un público heterogéneo, b) conferencias didácticas para los profesores secundarios, y c) el curso de seminario para los que aspiraban a ser historiadores.

A la manera de la época, un estudiante-Julio C. Moreno- se encargó de resumir y publicar las clases del seminario. Según estas notas, Altamira se

(7) Cabe recordar que el "hispanismo" era un elemento importante en el clima ideológico de los países de Latinoamérica. En la transición del siglo XIX al XX, en el caso de Argentina se produce una reconsideración de la "herencia española" y una nueva visión del pasado alimentada por el "mito de la raza".

(8) Carta de la presidencia de la Universidad invitando al acto de recepción de Altamira, (Caja n $\left.{ }^{\circ} 1, \mathrm{AHCN}\right)$. detuvo en cuestiones pedagógicas tales como el papel de los profesores, las actividades de los alumnos, la organización de los programas, el uso de libros y la crítica a los manuales, los elementos auxiliares de la enseñanza de la historia, la finalidad de la enseñanza de la historia y la formación del espíritu nacional. También desarrolló otros temas relacionados con el diseño del saber, explicando cómo tomar notas y cómo organizar el conocimiento y la lectura de las fuentes. Las conferencias públicas fueron veinte, se publicaron en la prensa local y se reprodujeron en algunas revistas de educación.

Destaquemos que Altamira, frente a otros, subrayaba la definición de la historia como ciencia y de ahí las consecuencias que eso tenía en la metodología a adoptar, en el uso de las fuentes y en la educación del historiador argentino. Con respecto a este punto, recomendó que los futuros historiadores se concentraran en la historia de su país y no perdiesen tiempo en la europea (que no estuviese relacionada con su historia), incluyendo en esto períodos anteriores a la vida independiente. Para el desarrollo de esos estudios insistió en la publicación de documentos y fuentes, el establecimiento de escuelas anexas a la Facultad de Filosofía (9), la realización de monografías de carácter local, y la exploración de las fuentes monumentales y las excursiones allí donde se encontraran "supervivencias de pueblos antiguos".

Asimismo, postuló la creación de una Junta Histórica como la RealAcademia de España o laSociété des Savants de Francia y la conveniencia de fomentar centros auxiliares de la investigación histórica en la que podrían participar aficionados a la historia y eruditos provinciales. En relación a esto indicó que había que coleccionar y distribuir espacialmente las exploraciones, crear museos de carácter "privisional" (sic) (10), huir de la centralización del trabajo, hacer clasificaciones de carácter regional. Si bien fomentó los estudios históricos de carácter nacional y regional, señaló que, para no caer en el "patrioterismo", se debían fundar museos de historia general de la humanidad, ya que todo pueblo estaba relacionado entre sí.

Además hizo una crítica a los programas de historia de las escuelas argentinas, ya que constituían

(9) Altamira pronunció estas palabras en una facultad que no era específicamente de Filosofía, sino de Ciencias Jurídicas y Sociales. Con ellas se inauguraba la "Sección de Filosofía, Historia y Letras".

(10) Es de destacar la cantidad de errores de tipografía y de redacción que tienen estas publicaciones dedicadas a maestros y estudiantes de pedagogía. 
un plan regresivo y representaban un exceso de historia nacional sobre todo en los aspectos políticos. En este sentido señaló la falta de una historia de la civilización y de un marco que remitiera a la vida internacional. Era necesario que, primero el niño, en lecciones de cosas, comprendiera la historia humana en general para, después, especializarse en el sujeto americano y de esta forma no perder de vista el conjunto. Asimismo, la Facultad de Filosofía y Letras de la Universidad de Buenos Aires aprovechó la oportunidad para brindar un curso semejante con el mismo profesor que fue "muy concurrido y obtuvo el éxito que esperaba" (Anónimo, 1910: 250). Las clases deAltamira fueron muy promocionadas y difundidas en circuitos que excedían los meramente universitarios.

Con respecto a la arqueología, Altamira difundía en sus cursos lo ya publicado en Madrid en 1892 bajo el título de "Enseñanza de la Arqueología Nacional". En esta nota intentaba aportar nuevas noticias y argumentos sobre la enseñanza concreta de las arqueologías nacionales tomando como guía un trabajo de Langlois, profesor de la Sorbona, que no hacía mención a la arqueología geológica. Este marcaba las diferencias entre las enseñanzas artísticas en las universidades de Alemania y Francia, sobre todo en lo referente a la historia del arte de la Edad Media y Moderna, donde había que buscar las fuentes de las especificidades nacionales.

Langlois afirmaba la necesidad de educar el gusto de la juventud, que miraba el pasado de manera displicente: "así, los más refinados de la generación joven aprecian mal el arte del pasado. Viven en medio de las reliquias que cubren nuestro suelo y ocupan nuestros museo, con indiferencia y sin comprenderlas" (Altamira, 1892: 53). Sin embargo, señalaba que esto había sido comprendido por los estudiantes franceses quienes, en su Asociación de París (11), habían organizado una serie de conferencias de arqueología, dada por especialistas. Asimismo, los estudiantes de la Escuela Normal participaban en las "excursiones arqueológicas" de los alumnos de la Escuela de Cartas y habían inaugurado paseos artísticos al Museo de Trocadero y a Nôtre Dame. Pero Langlois indicaba que la visita a los monumentos sería poco provechosa si no se acompañaba con explicaciones técnicas y profesio-

(11) Desde 1891 existía una organización general que nucleaba a los estudiantes: la Association générale des éstudiants de Paris, con biblioteca, sala de lectura y en la que se organizaban conferencias semanales para que los estudiantes se ejercitaran en debatir las cuestiones difíciles, muchas veces presididas por los profesores de la Facultad (Quesada, 1906 y Guichard, 1911). nales: la educación del gusto no debía dejarse librada a las impresiones y a los lugares comunes que circulaban sobre los monumentos sino que debían ser puestas al día a partir de los conocimientos científicos. En este sentido, era importante la presencia del profesor en las excursiones y visitas a museos, personal con el que contaban las Facultades francesas y que también podrían iniciar una tradición en la enseñanza de esos estudios. Sus observaciones no se dirigían a proponer una reforma en los planes de segunda enseñanza, sino que apuntaban a la modificación de la universitaria, entendiendo que el mejoramiento de la primera vendría como reflejo de la segunda. Para ello, los temas de historia del arte tendrían que formar parte de los exámenes de agregación para que fueran estudiados con detenimiento. Langlois no desconocía el gasto que estas ideas aparejaban y proponía su solución: conferencias de los profesores y uso de las grandes colecciones arqueológicas y artísticas del país, de las que el Estado francés era editor o suscriptor.

Para Langlois, el modelo seguía siendoAlemania y Altamira recurría a este diagnóstico general para argumentar que si, en Francia con materias de Historia del arte en las Facultades de Letras y con escuelas especiales donde se estudiaba arqueología, se lamentaban de la "incultura” de la juventud, ¿qué se podía esperar en España?, donde sólo se daban esas clases en la Escuela de Diplomacia. Altamira terminaba su artículo señalando que, a diferencia de Francia, tal vez uno de los problemas más graves para incorporar esos estudios en los programas oficiales españoles sería el de contar con profesores para esos temas. Altamira, tomaba aAlemania como ejemplo a seguir en lo que respecta a la relación entre estudiantes y profesores y la metodología de la enseñanza en general.

En esto hay que destacar la situación algo paradójica que se planteaba en laArgentina con respecto a la valoración de los países del sur europeo. Las relaciones con España y con Italia contaban con el camino allanado dados los vínculos lingüísticos y cierta disposición de dinero puesta por los miembros de estas colectividades que se habían enriquecido en la Argentina y patrocinaban los intercambios intelectuales (Fernández y Moya, 1999). Por otro, la "descalificación" de esos mismos países se hacía de manera diferencial: mientras que Italia sobresalía por su ley de protección de antigüedades (Endere y Podgorny, 1997), la situación española se veía bajo el dominio de la enseñanza de la historia sagrada y con una organización escolar arcaica 
(Rojas, 1909: 256). En ello Rojas retomaba el diagnóstico de Rafael Altamira (1894) y concluía: “el ímprobo trabajo de reconstruir ese pasado débele poco á las universidades españolas. En cambio, meritorios esfuerzos individuales, sociedades de provincia y Academias como la de Historia, la de la Lengua ó de San Fernando han prestado, cada una en el terreno de sus especialidades, inestimables servicios á la Nación" (Rojas, 1909: 260-261).

Con ello se debe ver una impugnación a lo que era percibido como un anacronismo en la institucionalización de las ciencias, en la que las universidades españolas parecían no haber asumido la función que se les adjudicaba como natural. Sin embargo, este diagnóstico no derivaba en un desconocimiento de las tendencias y de los libros producidos en España. Muy por el contrario, las obras deAltamira se compraban para proveer las bibliotecas de maestros y las bibliotecas particulares argentinas en el marco de una comercialización importante de libros y colecciones editadas y traducidas en España.Así se difundieron las obras sobre la enseñanza de la historia que promovían las bibliotecas como la de " $\mathrm{Da}$ niel Jorro" de Madrid, que publicó una serie de traducciones del inglés y del francés sobre la historia en los inicios de la década de 1910 (12).Asimismo, Rojas incluye a España en su programa de visitas.

Las conferencias de Altamira en la Argentina caían en un marco de reforma de la enseñanza secundaria y pedagógica. Destaquemos que en 1903, de acuerdo con un decreto del Poder Ejecutivo de la Nación sobre requisitos para ser profesor de enseñanza secundaria se organizaron los cursos de HistoriaArgentina, ArqueologíaAmericana y Ciencias de la Educación, "donde se debían obtener los certificados de competencia" (Rojas, 1909: 439). En 1907 esta medida se complementó colocando al Instituto Nacional del Profesorado Secundario bajo la Superintendencia de la Facultad de Filosofía y Letras de Buenos Aires, sustrayéndolo del control directo del Ministerio de Instrucción Pública. Como Rojas (1909: 439, nota 2) señalaba esto era percibido como un intento de "poner la enseñanza media bajo la dependencia de las autoridades científicas y no políticas o administrativas simplemen-

(12) Entre otras, la Biblioteca científico-filosófica de Daniel Jorro publicó El estudio y la enseñanza de la historia de B.A. Hinsdale (obra de 1893, traducida por Domingo Barnés, Secretario del Museo Pedagógico Nacional, en 1912) e Introducción a los estudios históricos de Langlois y Seignobos (obra de 1897, traducida por Domingo Vaca en 1913). Esta misma editorial difundía las obras de los argentinos Carlos Octavio Bunge, José Ingenieros y Víctor Mercante. te» (13). En La Plata, la formación de los profesores de enseñanza secundaria se incluyó en la Sección Pedagógica de la Facultad de Ciencias Jurídicas y Sociales, estableciéndose un sistema de correlación por el cual las asignaturas científicas (las correspondientes a ciencias naturales y etnografía) se seguían en el Instituto del Museo de La Plata (Universidad Nacional de La Plata, 1910). Esta Sección junto a la de Filosofía, Historia y Letras, pasó a formar parte de la Facultad de Ciencias de la Educación creada en 1914. En el programa del doctorado en historia se incluyó la materia Prehistoria argentina y americana, que fue dictada por Luis María Torres entre 1911 y 1932 (14).

Por otra parte, en 1910, desde el Ministerio de Justicia e Instrucción Pública se proyectó una Escuela Normal Superior de la ciudad de BuenosAires, para la especialización de los docentes en diferentes áreas. Para ello se recurrió a profesores de la Universidad de BuenosAires. En el área de las ciencias sociales se incluyó la materia arqueología a ser dictada porAmbrosetti, quien también se encargó de la formación de un museo etnográfico y arqueológico escolar para el dictado de las clases. Esta Institución no tuvo mucha vida y las colecciones etnográficas compradas para el museo escolar, fueron donadas por el Ministerio al Museo Etnográfico. Asimismo, en esa época también el Consejo Nacional de Educación consultó a profesores -investigadores universitarios para la conformación de planes de estudio para reformar la enseñanza normal. Con ese motivo, Torres elaboró un programa de historia general y otro de historia nacional, en el que se incluían nociones de arqueología que, aunque no oficializados, se incorporaron en algunas escuelas normales (15). Ligado a la expansión de estos pro-

(13) Este decreto fue derogado en 1909.

(14) Inicialmente estos contenidos estaban incluidos en una materia de Historia.

(15) En primer año de historia general se incluía: nociones de prehistoria, carácter científico de esta historia. Las fuentes de la prehistoria é historia. Las civilizaciones deAsiria, Persia y Egipto. Los museos de antigüedades. Grecia y su civilización. Roma y su civilización. (Sinopsis gráfico-cronológico de las civilizaciones y ejercicios históricos geográficos sobre croquis). En segundo año, comenzaba el programa de Historia Argentina que se desarrollaba en cuatro años y se dividía en: antigua, descubrimiento y conquista, colonial, y revolución, independencia y constitucional. La parte antigua comprendía: los tiempos prehistóricos y su clasificación, carácter de la cronología, Nociones de geología, antropología, arqueología, etnografía y linguiística y sus aplicaciones al problema del hombre primitivo deAmérica; condiciones geográficas del territorio americano. Principales divisiones geoétnicas americanas y argentinas. Caracteres físicos, intelectuales, sociales de los primitivos pobladores y de los modernos y de los modernos indígenas del territorio argentino (exposición y consulta facultativa de la fuentes, $y$ ejercicios históricos-geográficas sobre croquis) (Mercante, 1912). 
gramas en los que se planteaba extender el conocimiento de la historia patria a sus épocas pre y proto históricas, se suscitó también un movimiento de pedido y suministro de materiales sobre el pasado, de visitas y de clases en los museos públicos.

Un aspecto a recalcar es la diferencia entre los "duplicados" y los objetos reproducidos en materiales como yeso o papel maché. Los primeros se referían a objetos originales, de los que ya se tenía un ejemplar tipo y, como los casos del Museo Etnográfico y de La Plata, se intercambiaban o se donaban a museos escolares y a las colecciones de escuelas normales. En ese marco, las colecciones de los museos centrales más que acumular todo adoptaban la política de conservar sólo los ejemplares representativos de formas y estilos o los especímenes tipo. Esta política no se modificó con el establecimiento de la ley de patrimonio en 1913 ni con su posterior reglamentación en 1921 (cf. Endere y Podgorny, 1997). Pero, subrayemos, sólo se permitía la salida al exterior de reproducciones en yeso mientras que para la exportación de los objetos duplicados se precisaban varias autorizaciones. Dentro de las fronteras nacionales, por el contrario, esas piezas circulaban libremente fuera en calidad de préstamo, donación o compra.

\section{LA TRANSMISIÓN DE LA APTITUD TÉCNICA}

\section{a) Los museos y los materiales de enseñanza}

\begin{abstract}
"El trabajo de las clases de historia no debe encaminarse tanto á sacar conclusiones en el tema propuesto, como á ofrecer motivos de prácticas que produzcan la aptitud técnica consiguiente. Así, v. gr., por lo que toca á las inscripciones, deben los alumnos ejercitarse en sacar calcos, no sólo de las que se guardan en los Museos Arqueológicos sino también de las que subsisten en el suelo, los muros y las rocas de los lugares que visiten, para aprender á vencer las dificultades que ofrecen las piedras mal situadas, encaladas, etc., acostumbrándose a leerlas directamente y sobre los calcos, que no es lo mismo que encontrárselas ya impresas y restauradas" (Altamira, 1894: 436-437).
\end{abstract}

Las últimas décadas del siglo XIX corresponden a la consolidación de las "lecciones de cosas" basadas en las ideas de Froebel (Gómez R. de Castro, 1997) y de esa especie nueva que se llamó "imaginería escolar" (Podgorny, 1995). En este marco aparecía como relevante la distinción entre una enseñanza basada en el libro y en la exposición oral del maestro frente a otra "útil y agradable" basada en la "intuición" y en métodos realistas conectados con la observación y la comparación. La idea que el pensamiento personal del discípulo era excitado y provocado por la vista y por el manejo de objetos que había de conocer y estudiar se dio en llamar "intuición" y se proclamó como un elemento esencial en los métodos de educación modernos. Esta enseñanza reproduciría la manera científica de conocer y estaría de acuerdo con una nueva manera de relación con el mundo real que desenvolvería nuevas facultades y capacidades. La creencia que la inteligencia del sujeto, enfrentada directamente a las cosas, le permitiría descubrir su naturaleza es el punto de justificación y de partida de todas las iniciativas de la pedagogía basada en las "cosas" y en los objetos.

En esta corriente pedagógica cobraron importancia las excursiones, las visitas a los museos y el trabajo con los objetos dentro del aula siempre guiadas por el maestro que, como marcaba Langlois, debía guiar los sentidos para que arribaran a las conclusiones correctas. Por entonces, los museos constituían los lugares privilegiados para la investigación y formación de estudiosos en las disciplinas que gobernaban las colecciones. El museo a fines del siglo cada vez más tendía a ser visto como "una obra de enseñanza", cuyo poder no residía en el poder de los objetos, sino en la acción combinada entre la acción de la palabra del maestro y la exposición (Lopes, 1997; Podgorny, 1995). Eran estos los espacios públicos que articulaban la relación entre las investigaciones y un público que se ampliaba cada vez más, no sólo mostrando los objetos sino también aislando el gabinete del naturalista de las preguntas del aficionado al mundo natural.

Las exhibiciones de los museos de ciencias no necesariamente se basaban en la pieza original, muy por el contrario se creaba un universo con elementos que combinaba originales y réplicas de procedencia diversa, combinando lo exótico y lo local. Las reproducciones de materiales arqueológicos y paleontológicos para intercambiar piezas de comparación entre los museos se instauró como práctica a mediados del siglo XIX (Podgorny, 2000b). Pero, destaquemos, la idea de construir colecciones de réplicas para las instituciones de enseñanza ora universitarias, ora primarias o secundarias, aparece ligada a la acción educativa del museo más allá de la visita a sus salas y da lugar a un movimiento que defiende la difusión del uso de las mismas.

T. P., 58, n. $^{\circ} 2,2001$ 
La posibilidad de replicar objetos de la antigüedad, por otro lado, permitía no sólo la salida del museo para su uso en otros contextos, sino también la posibilidad de reunir en dichas colecciones de réplicas un conjunto aún más completo que el que albergaba el propio museo. En efecto, la reproducción permitía crear colecciones que juntaban piezas depositadas en los museos centrales con las de los museos de provincia y las piezas de colecciones privadas. De tal manera, el material de educación se erigía también como representación de diferentes instituciones e individuos. Destaquemos que las propuestas metodológicas para "el estudio de las antigüedades" incorporaban tanto las colecciones públicas como también las privadas.

En un contexto donde la compra y venta de los objetos arqueológicos y paleontológicos era algo admitido como parte de la logística de los museos y de las instituciones científicas, el armado de colecciones para las escuelas recurriendo a piezas originales no era algo, en principio, imposible. Sin embargo, el problema no residía en la posibilidad de su venta sino en el precio que estas piezas tenían en el mercado de antigüedades y de objetos de historia natural. Por lo tanto a fines del siglo XIX, se podía postular que la reproducción de objetos de la antigüedad ofrecía, entre otras, la ventaja de reducir el costo de las mismas y facilitaba su adquisición a las instituciones de menos recursos. Así por ejemplo, Altamira festejaba con Langlois que: "los medios de hacer estudios arqueológicos son hoy innumerables. El material de la ciencia arqueológica no ha sido jamás tan perfecto y barato como hoy en día. La fotografía, el heliograbado y los vaciados multiplican las obras maestras...Los progresos extraordinarios en el arte de la reproducción de los originales han producido, en nuestros días, una revolución análoga á la que trajo la difusión del arte tipográfico en el siglo XV: el uno ha vulgarizado el pensamiento, los otros facilitan la enseñanza de la arqueología en todos los grados, popularizando la inteligencia de las cosas de arte" (Altamira, 1892: 53).

El profesor de la Sorbona recomendaba los materiales del editor Braun y los producidos en el museo del Trocadero señalando la posibilidad de organizar "galerías incomparables" de réplicas en base al buen gusto del especialista. Frente a esta alternativa moderna, los museos de provincia y la exhibición de originales locales aparecían como lo opuesto, es decir, como los espacios donde los sentidos se podrían malformar. La réplica, ade- más, multiplicaba la pieza única las veces que fuera necesario. De tal manera, las colecciones reproducidas ponían "al alcance de todos" los materiales dispersos, inaccesibles y caros. Asimismo, como recurso indispensable aparecía la fotografía, la cual había provocado una verdadera revolución en el orden de las investigaciones donde el principio fundamental era la observación y la comparación, ya que permitía multiplicar indefinidamente los elementos comparables (Babelon, 1910: 324-325). Tal como había previsto Baudelaire (16), la fascinación por la fotografía, la rapidez de la reproducción de las imágenes y la facilidad para su dispersión, se había instalado en el mundo burgués.

La posibilidad de la réplica y del armado de colecciones para la enseñanza fue una empresa prontamente asumida por las editoriales y las casas especializadas en productos pedagógicos y/o instrumentos y material científicos. Ligado a ello, en la sección dedicada a materiales de enseñanza de la exposición universal de Viena de 1873 los representantes alemanes, austríacos y franceses presentaron una colección de estampería (Berra, 1898; García e.p.; García del Dujo, 1985); y las casas Grimme (Viena) y Hestermann (Hamburgo), series que incluían materias primas y sus transformaciones en la producción industrial. Poco después, esto se vería como el origen de la tendencia a establecer colecciones de enseñanza y museos escolares. De hecho, la incipiente industria escolar tomó a las siguientes exposiciones universales como el espacio natural para promocionar sus productos que, en Europa se venían desarrollando desde 1855 como manera de

(16) La distinción entre la función de la fotografía como ayuda memoria para las profesiones científicas y como posibilidad de detener la destrucción de los objetos del tiempo a través y como enemiga de la poesía (y del alma humana) fue una de las reacciones que surgieron al aparecer esta técnica. Benjamin (1986: 875), en sus anotaciones sobre París y el siglo XIX recoge las siguientes ideas de Baudelaire: "Il faut donc qu'elle (la photographie) rentre dans son véritable devoir, qui est d'être la servante des sciences et des arts, mais la très-humble servante, comme l'imprimerie et la sténographie, qui n'ont ni crée ni supplée la littérature. Qu'elle enrichesse rapidement l'album du voyageur et rende à ses yeux la précision qui manquerait à sa mémoire, quélle orne la bibliothèque du naturaliste, exagère les animaux microscopiques, fortifie même de quelques renseignements les hypothèses de l'astronome; qu'elle soit enfin le secrétaire et le garde-noe de quiconque a besoin dans sa profession d'une absolue exactitude matérielle, jusque-là rien de mieux. Qu'elle sauve de l'oubli les ruines pendantes, les livres, les estampes et les manuscrits que le temps dévore, les choses précieuses dont la forme va disparaître et qui demandent une place dans les archives de notre mémoire, elle sera remerciée et applaudie. Mais s'il lui est permis d'empiéter sur le domaine de l'impalpable et de l'imaginaire, sur tout ce qui ne vaut que par ce que l'homme y ajoute de son âme, alors malheur à nous!". 
presentación y difusión de las industrias y materias primas de los diferentes países. Especialmente, las exposiciones tenían dos tipos de público: el que visitaba la exposición y el que leía los catálogos de la misma. Por otro lado, las industrias que exhibían sus productos multiplicaban el efecto de promoción a través de la edición y exhibición de los catálogos de la casa con los precios y las condiciones de venta y envío. En el caso de las fábricas y casa proveedoras de material didáctico, generalmente se acompañaban estas descripciones con referencias a las lecciones que se podían desarrollar por medio del manejo de dichos materiales. Los objetos presentados constituían sólo una muestra de la calidad, mientras que los premios obtenidos en las Exposiciones pasaban a engrosar los catálogos, el valor y el prestigio de la casa.

Las empresas francesas y alemanas desarrollaron una amplia gama de láminas, colecciones didácticas, juguetes, gabinetes de experimentación, mapas, a la vez que editaban y exportaban libros a distintos países (17). La competencia entre las industrias escolares francesas, alemanas, austríacas e inglesas por imponer los productos en los mercados coloniales y latinoamericanos no es diferente a la que se dio en otros ramos de la industria y de la expansión imperiales (Hobsbawm, 1995; SheetsPyenson, 1989; Pyenson 1985). En relación a este aspecto, al analizar objetos tales como los libros de texto, el mobiliario y el material escolar, uno se enfrenta no sólo con las políticas educativas sino también con el problema de la industria editorial y de los materiales pedagógicos cuya expansión se produce en la segunda mitad del siglo XIX (Richter, 1992). En el caso de las réplicas de antigüedades y también de objetos etnográficos, al igual que en muchas otras áreas, los modelos desarrollados en Alemania aparecían como los más avanzados y competían con los franceses (Vitry, 1898).

La idea que las naciones hispano-americanas debían desarrollar "modelos nacionales" que sustituyeran a los promovidos por las casas francesas y alemanas, era una idea compartida por los pedagogos españoles y argentinos (Senet, 1891; Mercante, 1893; Lugones, 1910). Frente a ello surgió el problema de los criterios de armado de las coleccio-

(17) Entre las firmas internacionales que tuvieron difusión en la Argentina se puede mencionar la casa Johnston de Londres y Edimburgo, la casa Deyrolle de París, Sociedad Louis Michaud y la casa alemana K. F. Koehler, que tenía una sucursal en Buenos Aires y editaba catálogos en español para el mercado latinoamericano.

T. P., 58, n. $^{\circ} 2,2001$ nes para lograr con eficacia una educación nacional. Así, el pedagogo Víctor Mercante expresaba: "Las obras plásticas de nuestros gabinetes de Ciencias Naturales, esmeradamente hechas, no representan una planta, una flor, un fruto argentino. Las telas ilustrativas, en Europa son hechas y a Europa retratan; las colecciones mineralógicas, de productos agrícolas, las cajas enciclopédicas (por otra parte muy deficientes) cuando no vienen de Francia son deAlemania. Pero ¿somos franceses o argentinos?" (Mercante, 1893: 15).

Altamira, luego de su viaje a América del Sur, tomaría el ejemplo de estos países como inspirador de la relación de control que el Estado debía asumir en la supervisión de la construcción y distribución de los materiales de enseñanza. Para Altamira tomar el caso sudamericano en oposición a los franceses y alemanes tenía el valor adicional de suministrar un ejemplo tomado de la misma raza.

En la Argentina, la idea de la reproducción de piezas y de armado de colecciones para la educación general se promovía desde el Museo Nacional, Etnográfico y de La Plata y durante el Ministerio de Instrucción Pública de la Nación de Joaquín V. González (1904-1906). Uno de sus objetivos era imprimir a los estudios secundarios y normales un carácter regional.Acompañó su gestión como Inspector General de la Enseñanza Secundaria y Normal, el escritor Leopoldo Lugones. Para Lugones, las ciencias naturales constituían el vehículo más apropiado, ya que consideraba que no era posible darle una carácter regional ni a las matemáticas ni a las letras. Mencionaba que: "a objeto de nacionalizarla, o mejor dicho provincializar la enseñanza, no hay otro medio conocido que vincularla con las peculiaridades de cada región; y esta es indispensable, por otra parte, al método experimental que se preconiza" (Lugones, 1910: 161). Para ello, en 1905 propuso dos proyectos, uno se refería a la formación de colecciones mineralógicas argentinas encargándoselas a la Escuela de Minas de San Juan y a la Facultad de Ciencias de Córdoba. El segundo consistía en modelar en yeso fósiles típicos argentinos, pidiéndole a FlorentinoAmeghino, director del Museo Nacional, que le indicara los cien ejemplares más típicos y fáciles de reproducir. De los sugeridos, algunos pertenecían a las colecciones del Museo Nacional, otros al Museo de La Plata y más del cincuenta por ciento a la colección particular de Ameghino. Estos proyectos, aunque no se realizaron, marcan un rasgo interesante en el sentido de la importancia que asumían los fósiles como 
símbolos de lo regional y de lo local (Podgorny, 1997; 2000c). Las escuelas, por su parte, solicitaban al Museo "fósiles pampeanos" para ilustrar sus clases (18).

En cuanto al material para la enseñanza de la historia, Altamira mencionó en sus conferencias de La Plata la importancia de la creación en cada centro docente de un museo escolar de historia cuando no hubiese algún gran museo cerca, y que en la ciudad de La Plata se volvía innecesario (Lám. I). Para los casos en que hubiera que formar colecciones de "material vivo" (19) para las escuelas, sugería: recurrir a los alumnos ya que en todos los hogares había objetos diversos procedentes de viajes, excursiones, observaciones; solicitar donaciones de duplicados o reproducciones de otros museos; crear secciones con "supervivencias vivas» (20), con mapas físicos e históricos, cuadros geográficos, mapas mudos apizarrados, láminas, fotografías, aparatos y material de proyecciones. Para la enseñanza de la historia general indicaba que muchos de esos materiales se podían adquirir en varias casas internacionales, aunque tenían el inconveniente de ser "demasiado" alemanas, en el sentido de referirse a la Edad Media y Moderna de Europa. Altamira señalaba que los centros científicos podrían colaborar en la formación de los museos escolares con duplicados, reproducciones de documentos, fotografías y suministrando datos.

En el caso del Museo de la Plata, desde fines del siglo XIX poseía los talleres necesarios y el personal capacitado para las reproducciones en yeso o papel maché de fósiles u objetos arqueológicos y se intercambiaban con instituciones análogas tanto nacionales como internacionales. Las solicitudes y envíos de réplicas y de objetos arqueológicos a establecimientos educativos, por otro lado, empiezan a generalizarse en los inicios de la década de 1920, respondiendo a una doble política. Por un lado, la de la nueva dirección del Museo (desde 1919 y hasta 1932 a cargo de Luis María Torres) que pretende renovar las vitrinas, ordenar las colecciones a partir de piezas auténticas y de procedencia conocida, facilitar la exposición y hacer más inteligible

(18) Documentos varios - AHCN.

(19) Se estimaba como "material vivo" a los objetos y láminas que debían ser "movibles" dentro del aula, en oposición al material clasificado y dispuesto de manera fija en las vitrinas de un gran museo.

(20) Bajo el término de "supervivencias vivas" se incluía a leyendas, tradiciones y canciones del carácter primitivo indígena que se consideraba que se estaban perdiendo frente a la inmigración extranjera. para el público las salas de exposición. Para esto último, se recibió un subsidio del Ferrocarril del Sur, asociado a la promoción turística de La Plata y su Museo que esta compañía realizaba (21). Torres, por su parte, logró configurar una amplia red de difusión del museo, tranformándolo no sólo en un icono científico sino también casi como una autoridad independiente tanto de la universidad como de los vaivenes de la política. Además le dio una importancia mayor a la difusión de la prehistoria y protohistoria argentinas, reeditando la parte que él había escrito en 1917 en un manual para el profesorado secundario como un libro aparte dedicado al mismo público (Podgorny, 1999b).

Destaquemos que ante los pedidos difusos (no definidos) de materiales de parte de las escuelas se puede detectar un cambio: mientras en la dirección anterior se optaba por colecciones de fauna o de minerales argentinos, Torres envía objetos e ilustraciones referidos a los pueblos indígenas del pasado. Por otro lado, los pedidos provienen de instituciones que surgen en esta época como las facultades de pedagogía de las nuevas universidades nacionales del Litoral y deTucumán y los museos municipales. Asimismo, viejas instituciones como las escuelas normales y los gabinetes universitarios de la Universidad de Córdoba pretenden reordenarse y modernizarse a través de la constitución de gabinetes de estudio. En este sentido, se pueden señalar dos cosas: la centralización de las funciones del Museo de La Plata como un espacio recopilador de información y de colecciones, desde donde se redistribuirían hacia las otras instituciones provinciales y regionales; por otro, el peso que lo etnográfico/arqueológico va asumiendo en paralelo a los fósiles. Durante la década de 1920 se expande el tópico y motivos basados en las culturas indígenas como rasgo representativo de lo autóctono americano. La pródiga y grandiosa naturaleza argentina expresada en los

(21) Con relación al Ferrocarril Sur, la empresa le concedía al Museo un $50 \%$ de descuento en el transporte de las colecciones y materiales. También por ejemplo el gerente, solicitaba visitas al Museo. Además el Ferrocarril promocionaba "un día en La Plata. Excursión económica. Visita al Museo y exposición de avicultura. Boletos especiales de ida y vuelta....". Asimismo, los domingos (uno de los días de visita, además de los jueves) el ferrocarril expendía boletos de excursionistas a precios reducidos (también había boletos de segunda clase, que eran más baratos) (Caja n. ${ }^{\circ}$ 21. AHCN) Por otro lado, tanto el Museo de La Plata como el Etnográfico estaban incluidos en los circuitos turísticos que se ofrecían a los visitantes extranjeros y en los tours de turistas de EE.UU. Así la American Express company de Nueva York, pretende organizar una visita para un contingente de turistas norteamericano en 1921 como había ocurrido el año anterior que se rechaza por estar el museo en reparaciones (Caja n. ${ }^{\circ} 21, \mathrm{AHCN}$ ). 


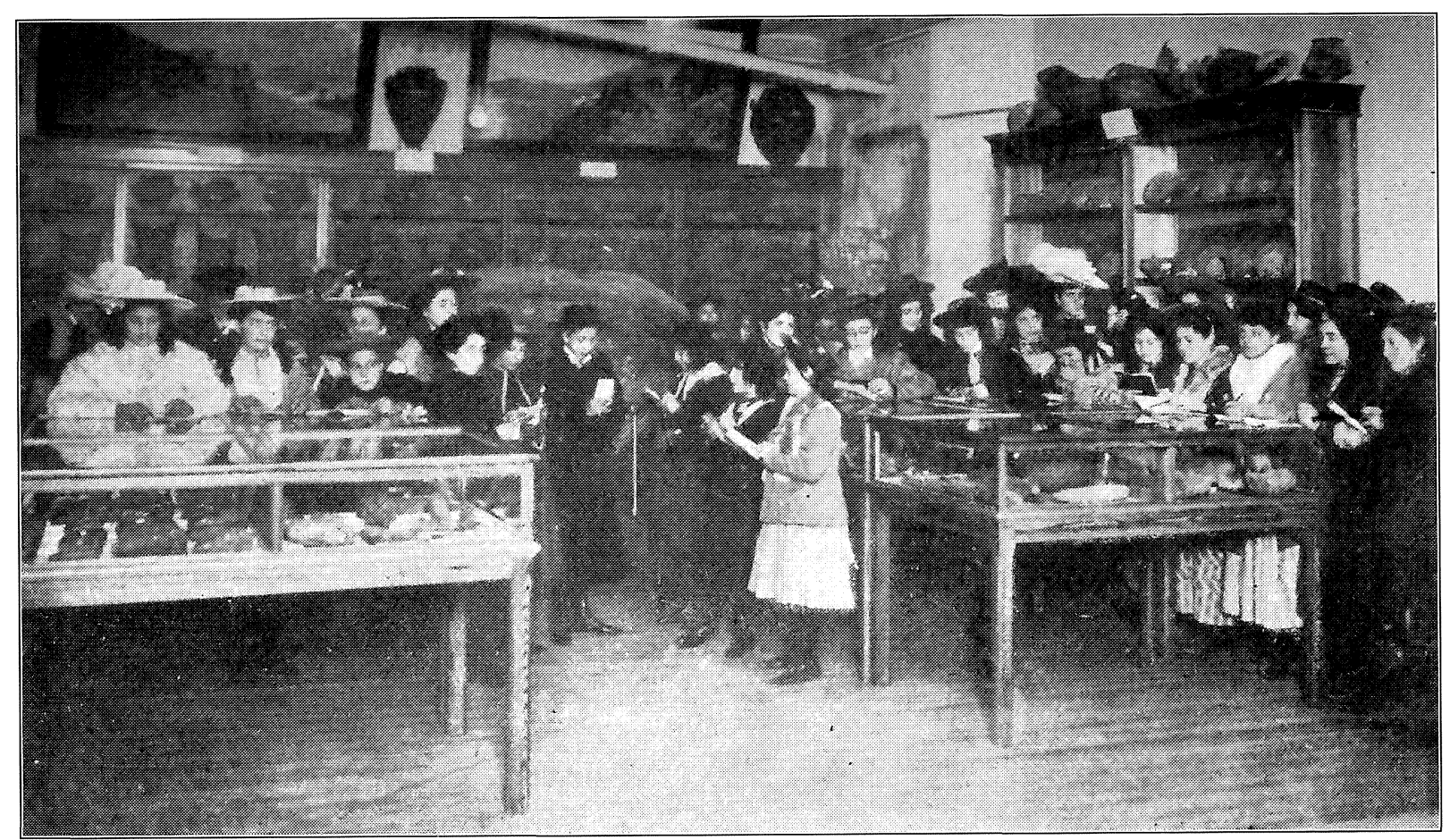

Lám. II. Excursión escolar al Museo Etnográfico de la Facultad de Filosofía y Letras de Buenos Aires en 1905, integrada por alumnas de $4 .^{\circ}$ a $6 .^{\circ}$ grado de la Escuela primaria Sarmiento. Allí se tomaron bocetos de los objetos que luego se reprodujeron en el contexto escolar (tomada de López, 1906).

mamíferos fósiles compartiría entonces su lugar con una cultura de raigambre americana.

En cuanto a las colecciones etnográficas y arqueológicas, en las Memorias del Museo de La Plata de mediados de la década de 1910 se señalaba que, seguramente debido a la nueva exhibición y a la mejor presentación de los materiales, la sección etnográfica había sido muy visitada, muy especialmente por profesores y alumnos de colegios y escuelas, y aún de la Universidad de Buenos Aires.Asimismo, se subrayaba que: "los cursos que se dictan en nuestra Universidad, como los de antropología, etnografía y prehistoria argentina y americana, han utilizado todo o la mayor parte del material clasificado, habiéndose dado catorce lecciones por profesores y alumnos en el mismo local donde las mencionadas colecciones se exhiben." (Lafone Quevedo, 1917: 102-103).

La experiencia de algunos pedagogos que se habían perfeccionado en Estados Unidos hace que los materiales del Museo Etnográfico no sólo sean utilizados por los estudiantes universitarios sino que pretende incorporarse inmediatamente en la enseñanza de niñas de educación primaria. Así, el caso de Ernestina López, autora de manuales escolares profusos en fotos provenientes de los museos (Podgorny, 1999 b), quien proponía "la tendencia modernísima de la enseñanza manual" organizada "sobre la base de la verdad científica" (López, 1906: 124) (22). La idea de reproducir las distintas fases de la civilización y de la industria se veía estimulada por la visita al museo de la Facultad de Filosofía y Letras (Lám. II), donde las vasijas calchaquíes, los textiles y la cestería, inspiraban la realización de reproducciones por parte de las alumnas (Lám. III). Por otro lado, se suponía que, mediante el trabajo manual que replicaba las formas pasadas, se exponía al niño a la repetición de los estadios de la evolución de las técnicas, quien lo aprehendía no de manera teórica sino experimental y empática. Además este Museo fue incorporado a las actividades educativas de varias escuelas comunes y normales a fines de la década de 1910, institucionalizándose las visitas anuales como parte de los programas de enseñanza de la historia.

(22) "El concepto de esta escuela podría sintetizarse diciendo que entiende como el fin primordial de la enseñanza poner al niño en condiciones de que sea capaz de interpretar el alcance de la civilización actual, único medio de exigirle su cooperación á la obra humana, cuyo espectáculo no debe quedar fuera del círculo de su comprensión, vale decir, de su simpatía" (López, 1906: 124). 


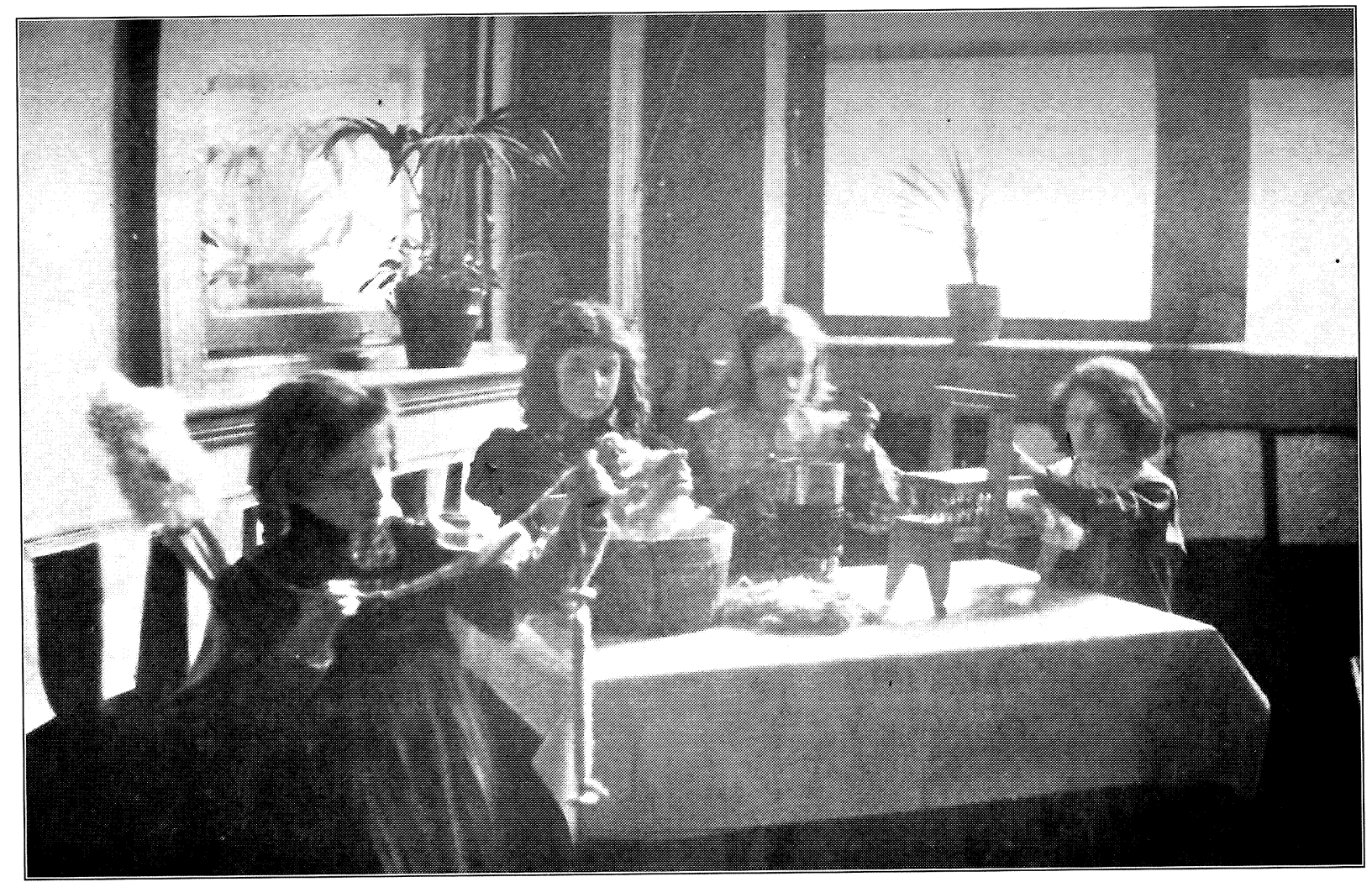

Lám. III. Alumnas aprendiendo a hilar según “procedimientos primitivos” (tomada de López, 1906).

\section{b) Las excursiones}

La enseñanza basada en la observación in situ de la naturaleza y de los objetos y los lugares históricos puede rastrearse también en conexión al mismo programa. A este respecto cabe destacar que como parte de la "Nueva escuela" las salidas del aula para, a través de la observación y la intuición, reproducir los caminos del conocimiento de las ciencias se consideraban como un elemento importante del proceso de aprendizaje. Además las excursiones fueron concebidas como un ejercicio de enseñanza integral en donde era posible combinar la educación física, los comentarios históricos-artísticos y de otras materias y una educación moral a través de la convivencia entre profesores y alumnos.

La Universidad de Oviedo tampoco estuvo ajena a esas tendencias (Uría, 1994). En este sentido, por ejemplo, se señalaba que: "en mucha de sus cátedras se ha abandonado la retórica disertación del profesor, sustituyéndola por la conversación, á la manera socrática, en que los discípulos entran como algo vivo; se les encomiendan memorias sobre temas de la asignatura; se hacen trabajos de índole completamente práctica en las asignaturas que á ellos se prestan...; se giran visitas á talleres, fábricas, minas, puertos, tribunales de justicia, prisiones; se realizan excursiones artísticas, arqueológicas en particular, y también recreativas, siempre mezclados alumnos y catedráticos, cuidando de que se haga reseña escrita de todas ellas" (Buylla, 1902:31).

Los "métodos modernos de investigación y enseñanza" fueron puesto en práctica por Rafael Altamira en su cátedra de Historia general del Derecho español, como medio para que el alumno entrara en contacto con la misma realidad histórica y se formara en el sentido de los hechos humanos y del proceso de su desarrollo. En esa materia, además de trabajar en el manejo, análisis y comparación de documentos históricos, se complementaron las lecciones con visitas al "museo de antigüedades asturianas para que vean inscripciones, monedas, calcos, pergaminos, etc., y en la cátedra hago circular á menudo fotografías, grabados, fototipias y otras reproducciones de documentos antiguos" (Altamira, 1902: 48).

Las "excursiones escolares" de carácter arqueológico o naturalista fueron implementadas, asimis- 
mo, en varias universidades españolas: Madrid, Sevilla, Valencia, Barcelona y Oviedo. En relación a ello, algunos profesores de esta última institución remarcaban que las excursiones constituían un "procedimiento educativo de primer orden; y no sólo para enseñar, sinó para que el profesor viva por algunas horas, ó por algunos días, en contacto con sus discípulos, los conozca y pueda dirigir su conducta moral y su educación física" (Sela, 1902: 179). Además apoyaron la reciente creación de la Unión Escolar Ovetense donde, era de esperar, se constituiría en su seno una sociedad dedicada a organizar esos útiles viajes, como había ocurrido con las asociaciones excursionistas de Cataluña que fomentaban el conocimiento de su provincia. Las excursiones para visitar monumentos y museos también formaron parte del programa de extensión universitaria desarrollado en la Universidad de Oviedo.

Pero, señalemos, en la enseñanza y la práctica de las ciencias como la antropología y la arqueología, "el campo" en esos años estaba apareciendo como uno de los lugares donde el científico debía buscar el conocimiento. En efecto, si bien los viajes de exploración y las colecciones de materiales conformaron siempre un aspecto ineludible de los estudios geológicos, arqueológicos y de arqueología prehistórica (y de todas las disciplinas ligadas a la historia natural), el naturalista de campo (quien hacía la primera recolección del material) y el descriptor de la colección, no necesariamente estuvieron reunidos en un solo individuo sino hasta el tardío siglo XIX y el XX inicial (Kuklick y Kohler, 1996; Podgorny y Politis, 2000). En este sentido, es importante destacar que en la incorporación de las excursiones al programa de enseñanza universitaria de las ciencias se puede ver la consolidación de la práctica de campo como parte de las habilidades que el científico debía reunir en su formación profesional.

En la educación primaria argentina, el Consejo Nacional de Educación reglamentó las excursiones escolares en 1900 (Marengo, 1991), constituyéndose los museos y los jardines zoológicos como los lugares principales para la contemplación de la naturaleza para los alumnos de la capital. Para ellos los elementos ilustrativos del pasado aparecían reunidos en el Museo Histórico Nacional y en los monumentos a los próceres nacionales que se estaban construyendo en esa época. Estos monumentos también fueron objeto de excursiones escolares especiales. Al mismo tiempo, en varias escuelas provinciales se venían realizando excursiones a sitios que localmente se les atribuía un valor histórico y para la observación de la naturaleza, establecimientos industriales o construcciones urbanas (Zubiaur, 1897).Además durante esas salidas se recolectaban objetos para la formación de museos escolares (García, e.p.) (23).

También entre los estudiantes universitarios latinoamericanos se fomentó las visitas a museos y lugares históricos. En el primer Congreso Internacional de Estudiantes Americanos realizado en Montevideo a principios de 1908, se propuso, entre otras conclusiones, la glorificación de los grandes hombres y de las tradiciones americanas por medio de la propaganda oral y escrita y con la realización de peregrinaciones patrióticas a monumentos y sitios históricos (García, 2000). En laArgentina ese tipo de prácticas había alcanzado amplia popularización como se evidenciaba en el aumento de participantes a las peregrinaciones patrióticas a Tucumán en conmemoración de la independencia que se realizaron anualmente en el mes de Julio durante los primeros años del siglo XX. A esas peregrinaciones asistieron, con subsidios otorgados por el Estado, diversas asociaciones docentes y centros de estudiantes secundarios y universitarios de varias ciudades del país. En Méjico, un grupo de estudiantes entre los que se destacó la figura de José Vasconcelos fundaron el Ateneo de la Juventud y posteriormente la Universidad Popular Mexicana en 1912, en las que desarrollaron programas de extensión universitaria, conferencias y visitas guiadas a museos y lugares históricos (Melgar Bao, 1999).

En el contexto académico y respondiendo a los objetivos planteados institucionalmente, los estudiantes de la Facultad de Filosofía y Letras de Buenos Aires definían a las excursiones como necesarias para la enseñanza de la arqueología americana siempre que estuviera ligada al "carácter nacional". En efecto, en el Segundo Congreso Internacional de EstudiantesAmericanos el tema de las excursiones

(23) Las excursiones al aire libre formaron parte del programa de la Escuela Normal de Paraná (Provincia de Entre Ríos). Esta institución fue muy importante en la formación de profesores en la Argentina finisecular. Las excursiones y la formación de museos escolares estuvieron vinculadas al profesor italiano Pedro Scalabrini (1848-1916), quien entre 1872 y 1895 fue catedrático de esa Escuela Normal, además de dirigir el Museo de Paraná. Como parte de ese programa, Scalabrini recorría con sus alumnos las barrancas del Río Paraná buscando fósiles. Con ellos, formaría en 1891 un Museo Escolar que también incluía una sección de Etnografía (Mercante, 1927). Los maestros formados con Scalabrini difundieron la idea de las excursiones y los museos por las escuelas y distritos en los que trabajaron (García, e.p.). 
asumía un carácter americano, aprobándose la resolución de que se vería con agrado que: "en todas las Universidades deAmérica se organizaran excursiones arqueológicas de carácter nacional, en las que tomarán parte los alumnos de cada Universidad y todos aquellos aficionados a esta clase de trabajo" (Cabral, 1914: 518). A ello se sumaba la posibilidad que, realizándose en vacaciones y subvencionadas por los gobiernos nacionales o las autoridades universitarias, como, de hecho, lo eran los congresos, los campamentos de estudiantes y las peregrinaciones patrióticas, las excursiones fueran otro lugar de encuentro y de sociabilidad de los estudiantes americanos (García, 2000).

La estrecha relación -al estilo de Rojas- entre "valores científicos" y "la patria", parecía que podía encarnarse a través de las "investigaciones sobre el terreno, recolección de alfarerías, utensilios, piezas interesantes, cráneos, etc etc; descripciones detalladas de la comarca en que se realizan; apuntaciones de carácter científico que más tarde son completadas en los gabinetes y laboratorios de estudio de la Facultad" (Cabral, 1914: 519).

El estudio del "elemento nacional" a través de las excursiones arqueológicas a las distintas regiones se oponía a "la historia de las transformaciones geológicas", en el sentido que en esta, tal como era presentada por los "eruditos maestros", estaban ausentes las referencias argentinas y americanas. La similitud entre la retórica fundacional del Museo Etnográfico de la Facultad de Filosofía y Letras y la del alumno Jorge Cabral, presidente del centro de estudiantes de esa Facultad y representante de la misma ante un congreso internacional de estudiantes, debe comprenderse en el marco del papel que estos desempeñaban como "embajadores intelectuales" de sus respectivas instituciones. Por otra parte, esos encuentros servían para difundir las distintas experiencias educacionales y de difusión cultural realizadas por los estudiantes latinoamericanos (García, 2000).

Es importante destacar que el hecho que los estudiantes destacaran el "valor patriótico" de las excursiones y de los conocimientos arqueológicos se relaciona también con la función de estos cursos y con las carreras que la mayoría de los estudiantes de Filosofía y Letras seguía. En efecto, desde 1903 el curso de "arqueología americana" había pasado a ser una materia obligatoria para los profesorados secundarios en función de promover el conocimiento de la historia antigua de este suelo. Por lo tanto, los estudiantes que esgrimen este argumento no son sólo los futuros arqueólogos sino futuros profesores de educación secundaria que, efectivamente, ven en los sitios y en los objetos arqueológicos un interesante recurso para, "a través del trabajo constante que fecundiza y dignifica, unir íntimamente al ciudadano con el suelo de la patria" (Cabral, 1914: 518). Recordemos que en el planteo de Rojas, los restos arqueológicos eran vistos como "parte integrante del territorio y de la emoción misma de su paisaje" (Rojas, 1909: 458). Por otra parte, la vinculación entre el suelo y las "razas americanas" estaba siendo aceptada como la relación más importante en cuanto criterio ordenador de la etnología y arqueología locales. Así, la antropogeografía y la clasificación geográfica de los grupos indígenas del pasado y del presente no sólo habían sido adoptadas para ordenar las exhibiciones antropológicas del Museo de La Plata (Podgorny, 1999a) sino que también era asumido como problema a tratar por los estudiantes.

\section{A MODO DE CONCLUSIÓN}

Cabe remarcar que el proceso de institucionalización de la enseñanza de la arqueología ha ido delineando la distinción contemporánea entre investigación científica y educación. Esta separación no sólo enmascara que la investigación científica es el resultado de un proceso que implica la educación en una práctica científica y previo a ella la participación en un sistema de ideas y de categorías comunes transmitidos en el proceso de socialización primaria y secundaria, sino que también encubre la estrecha relación que investigación científica y educación tuvieron, por ejemplo, en los momentos correspondientes a la organización del estado nacional (Podgorny, 1999b).

En este trabajo quisimos mostrar que los campos científico y educativo eran sumamente permeables entre sí, imbricados de alguna manera con parte de un discurso oficial de tendencia nacionalista. Hemos tomado el caso de los programas escolares, las conferencias públicas, la organización de excursiones, las visitas a los museos. En este sentido, las ideas aprendidas en el contexto de la enseñanza de la ciencia pasan al "corazón" de la formación de los mismos científicos y de los profesores universitarios de historia y ciencias. Por otro lado, también pretendimos mostrar que las ideas acerca de la regionalización o nacionalización de los contenidos forman parte de un movimiento internacional y de la defen- 
sa de determinadas industrias locales y/o artesanales frente a la expansión de las casas alemanas y francesas. Las colecciones, las visitas a museos y a los monumentos, las réplicas e incluso la experimentación de técnicas pretéritas confluían en esta pedagogía basada en la observación de las cosas que, en nuestro país, podía traducirse en la descripción de una vasija de los tiempos protohistóricos.

Para finalizar queremos destacar lo siguiente: el desarrollo del material de enseñanza para la enseñanza de la historia y de la arqueología generó una abundante bibliografía desde fines del siglo XIX. Tanto las publicaciones, las estrategias pedagógicas como el material de enseñanza desarrollado formaron parte de una industria que produjo una innumerable cantidad de objetos. Lo singular de todo esto es que recurrentemente estas ideas reaparecieron a lo largo del siglo XX como si nunca antes se hubieran planteado, como si los objetos generados y las prácticas pedagógicas vinculadas a ellos se hubiesen disuelto en el aire. Quizás por el mero carácter de ser objetos de consumo de una sociedad que, así como crea discursos y objetos, los arroja prontamente al olvido para que puedan ser creados otra vez. Los materiales de enseñanza de la historia nos muestran también una de las facetas más eficaces del capitalismo: la historia no nos enseña nada, al contrario: el devenir de la sociedad incluso borra de la memoria los objetos con los cuales se constituye.

\section{AGRADECIMIENTOS}

Parte de los materiales aquí utilizados proceden de la investigación realizada en el Departamento de Prehistoria del Centro de Estudios Históricos, CSIC y la Institución Libre de Enseñanza en el marco de un convenio de cooperación internacional CSIC-CONICET hace ya varios años. I. Podgorny agradece toda la colaboración que encontró entonces y especialmente a Pilar López García, Directora del Centro de Estudios Históricos (actual Instituto de Historia), CSIC (Madrid) y la Institución Libre de Enseñanza (Madrid). Por otro lado, mucha de la bibliografía mencionada pudo adquirirse gracias a un Subsidio de Inicio de Carrera de la Fundación Antorchas de Buenos Aires, con el que también se está procediendo a la organización delArchivo Histórico de la Facultad de Ciencias Naturales y Museo de La Plata. También se agradece a los dos evaluadores del artículo por sus sugerencias y a la Fundación Rockefeller a través del programa "Pro
Scientia et patria: los museos en la formación del patrimonio nacional" del Museo Etnográfico de la Facultad de Filosofía y Letras de la Universidad de Buenos Aires.

\section{BIBLIOGRAFÍA}

AA.VV. (1989): El krausismo y su influencia en América Latina. Fundación Friedrich Ebert. Madrid.

Altamira, R. (1892): "Enseñanza de laArqueología Nacional". Boletín de la Institución Libre de Enseñanza, 26: $52-55$.

- (1894): La enseñanza de la historia. Victoriano Suárez. Madrid.

- $\quad$ (1902): "Historia general del Derecho Español. Notas sobre los procedimientos de enseñanza". Anales de la Universidad de Oviedo, 1: 45-49.

- (1911): Mi viaje aAmérica. Victoriano Suárez. Madrid.

Ambrosetti, J.B. (1906): Exploraciones arqueológicas en la Pampa Grande (Provincia de Salta), SecciónAntropológica de la Facultad de Filosofía y Letras. Didot. Buenos Aires.

- (1912): Memoria del Museo Etnográfico. Compañía Sud-Americana de Billetes de Banco. Buenos Aires.

Ameghino, F. (1880): La antigüedad del Hombre en el Plata. G. Masson. París y Buenos Aires.

Anónimo (1910): "El Museo Etnográfico". En: La Universidad Nacional de Buenos Aires. 1821-1910. Tragant. Buenos Aires: 257-265.

BABELON, E. (1910): "De la place que devrait occuper l'archéologie dans l'Education nationale". Revue Internationale de l'Enseignement, 60, 2: 320-332.

BARNES, D. (1917): "El material de enseñanza". Boletín de la Institución Libre de Enseñanza, 41: 193-203.

Benjamin, W. (1986): Parigi, Capitale del XIX Secolo. Giulio Einaudi. Turín.

Berra, F. (1898): Código de enseñanza primaria i normal de la Provincia de BuenosAires. Talleres de Publicaciones del Museo. La Plata.

BERTONI, L.A. (1992): "Construir la nacionalidad: héroes, estatuas y fiestas patrias, 1887-1891". Boletín del Instituto de Historia Argentina y Americana 'Dr. E. Ravignani'. Buenos Aires, 5: 77-111.

Borges, J.L. (1990): “El escritor argentino y la tradición”. En Discusión, incluido en Obras Completas, I. Emecé. Buenos Aires: 267-274, $1^{\text {a }}$ ed. 1932.

Buylla, A. (1902): "La Universidad de Oviedo en la actualidad". Anales de la Universidad de Oviedo, 1:2535 .

CABral, J. (1914): "La enseñanza de la arqueología americana deberá siempre complementarse con excursiones científicas de carácter nacional”. En Federación Universitaria de Buenos Aires: Relación oficial del Segundo Congreso Internacional de Estudiantes America- 
nos, II. Talleres Gráficos de la Penitenciaría Nacional. Buenos Aires.

Cortadella Morral, J. (1997): "La investigación arqueológica en las asociaciones excursionistas catalanas (1876-1915)". En G. Mora y M. Díaz- Andreu (eds.): La cristalización del pasado: génesis y desarrollo del marco institucional de la arqueología en España. Servicio de Publicaciones de la Universidad. Málaga: 273285.

Díaz Andreu, M. y Champion, T. (1996): Nationalism and archaeology in Europe. UCL Press. Londres.

ENDERE, M.L. y Podgorny, I. (1997): "Los gliptodontes son argentinos. La ley 9080 y la creación del patrimonio arqueológico nacional". Ciencia Hoy, BuenosAires, 7 , 42: 54-59.

FERNÁNDEZ, J. (1979-80): "Historia de la Arqueología Argentina". Anales de Arqueología y Etnología XXXIV$X X X V$. Universidad Nacional de Cuyo. Mendoza.

FERnÁNDEZ, A. y MoYA, J. (ed.) (1999): La inmigración española en la Argentina. Ed. Biblos. Buenos Aires.

GARCíA, S. (2000): “'Embajadores intelectuales’: El apoyo del Estado a los congresos de estudiantes americanos a principios del siglo XX". Estudios Sociales, Rosario, 19: 65-84.

- (e.p.): "Museo y Educación: la formación de los museos escolares a fines del siglo XIX". En Historia y Arqueología de la región pampa-patagónicas, II Jornadas de Historia y Arqueología del siglo XIX. Guaminí, 1999.

García del Dujo, A. (1985): El Museo Pedagógico Nacional (1882-1941). Teoría educativa y desarrollo histórico. Instituto de Ciencias de la Educación. Universidad de Salamanca.

Gellner, E. (1988): Naciones y nacionalismo. Alianza. Madrid.

Gómez-Pantoja, J. (1997): "Experto Credite. El P. Fita y el anticuarismo soriano". En G. Mora y M. Díaz-Andreu (eds.): La cristalización del pasado: génesis y desarrollo del marco institucional de la arqueología en España. Servicio de Publicaciones de la Universidad. Málaga: 197-205.

Gómez R. de Castro, F. (1997): "Lecciones de cosas y centros de interés". En A. Escolano Benito (dir.) Historia ilustrada del libro escolar en España. Del Antiguo Régimen a la Segunda República. Fundación Germán Sánchez Ruiz Peréz/Pirámide. Madrid: 449-466.

GuichARD, E.B. (1911): “Asociaciones estudiantiles francesas". Revista del Centro de Estudiantes de Derecho, Buenos Aires, 5, 24.

Hobsbawm, E.J. (1969): Industry and Empire. Penguin. Middlesex.

- (1990): Nations and nationalism since 1780. Cambridge University Press. Cambridge.

Hobsbawm, E.J. y Ranger, T. (eds.) (1983): The invention of tradition. Cambridge University Press. Cambridge.

InKSTER, I. y Morrell, J. (eds.) (1983): Metropolis and provinces. Science in British culture 1780-1850. University of Pennsylvania Press. Philadelphia.

KoHL, P. y FAwCET, C. (eds.) (1995): Nationalism, politics and the practice of archaeology. Cambridge University Press. Cambridge.

KuKLICK, H. y KoHLER, R.F. (eds.) (1996): "Introduction. Science in the field". Osiris, 11:1-16.

Lafone Quevedo, S. (1917): "Instituto del Museo". En Universidad Nacional de La Plata: Memoria General correspondiente a los años 1913,1914 y 1915. Imprenta Coni. Buenos Aires.

Lafuente, A.; Elena, A. y Ortega, M.L. (eds.) (1993): Mundialización de la ciencia y cultura nacional. Doce Calles. Madrid.

Langlois, C. y Seignobos, C. (1913): Introducción a los estudios históricos. Daniel Jorro. Madrid. $1^{\text {a }}$ ed. 1897.

LOPEs, M.M. (1997): O Brasil descobre a pesquisa científica. Os Museus e as ciências naturais no século XIX. Hucitec. São Paulo.

Lopes, M.M. y Podgorny, I. (2000): “The shaping of Latin American Museums of Natural History". Osiris, 15: $108-118$.

LÓPEZ, E. (1906): "Las actividades manuales en la escuela primaria. La enseñanza de la historia". El Monitor de la Educación Común, Buenos Aires, 26, 404: 124 140.

Lugones, L. (1910): Didáctica. Otero y cía. Buenos Aires.

MARENGO, R. (1991): "Estructuración y consolidación del poder normalizador: el Consejo Nacional de Educación". EnA. Puiggrós (dir.): Sociedad Civil y Estado en los orígenes del sistema educativo argentino. Galerna. Buenos Aires.

Melgar Bao, R. (1999): "Las universidades populares en América Latina 1910-1925”. Estudios, Córdoba, 1112: 41-57.

Melón, S. (1988): El Viaje de Altamira a América. Universidad de Oviedo. Oviedo.

Mercante, V. (1893): Museos escolares argentinos y la escuela moderna. Imprenta de Juan A. Alsina. Buenos Aires.

- (1912): "Los estudios históricos en las escuelas normales". Archivos de Pedagogía y Ciencias Afines, La Plata, $\mathrm{X}: 13-17$.

- (1927): Maestros y Educadores. II. Gleizer. Buenos Aires.

Mora, G. y DíAz-ANdreu, M. (eds.) (1997): La cristalización del pasado: génesis y desarrollo del marco institucional de la arqueología en España. Servicio de Publicaciones de la Universidad. Málaga.

Moreno, F.P. (1890): “El Museo de La Plata. Rápida ojeada sobre su fundación y desarrollo". Revista del Museo de La Plata, I: 28-55.

Morrell, J. y Thackray, A. (1981): Gentlemen of Science. Early years of the BritishAssociation for the Advancement of Science. Oxford University Press. New York.

Mortillet, G. (1867): "Promenades préhistoriques à 
l'Exposition universelle". Materiaux pour l'histoire positive et philosophique de l'homme, 3 (5 y 6): 181368.

Podgorny, I. (1995): “De razón a facultad. Ideas acerca de las funciones del Museo de La Plata entre 1880 y 1920". Runa, Buenos Aires, 22: 89-104.

- (1997): "De la santidad laica del científico: Florentino Ameghino y el espectáculo de la ciencia en la Argentina moderna". Entrepasados, Buenos Aires, 13: 37-61.

- (1999a): "De la antigüedad del hombre en el Plata a la distribución de las antigüedades en el mapa: Los criterios de organización de las colecciones antropológicas del Museo de La Plata entre 1890 y 1930”. História, Ciências, Saúde-Manguinhos, Río de Janeiro, 6 (1): 81-100.

- (1999b): Arqueología de la educación. Textos, indicios, monumentos. La imagen del indio en el mundo escolar. Sociedad Argentina de Antropología, Serie Tesis Doctorales. Buenos Aires.

- (2000a): "The Non Metallic Savages. The use of analogy in Victorian geological archaeology and French Paleoethnology and its reception in Argentina". EnA. Gramsch (ed.): Vergleichen als archaeologische Methode. BAR International Series. Oxford: 19-38.

- (2000b): "Los gliptodontes en París: las colecciones de fósiles pampeanos en los museos europeos". En M. Montserrat (ed.): La ciencia en la Argentina entresiglos. Textos, contextos, instituciones. Manantial. Buenos Aires.

- (2000c): "Archaeology and education in Argentina". Antiquity, 74: 151-155.

- (2000d): El argentino despertar de las faunas y de las gentes prehistóricas. Coleccionistas, museos, estudiosos y universidad en la Argentina, 1875-1913. Eudeba. Buenos Aires.

- (2001): "La clasificación de los restos arqueológicos en la Argentina, 1890-1940. Primera parte: La diversidad cultural y el problema de la antigüedad del hombre en el Plata". Saber y Tiempo, 3(12): 5-26. Buenos Aires.

Podgorny, I. y Politis, G. (1990/92): "Qué sucedió en la historia? Los esqueletos araucanos del Museo de La Plata". EnArqueología contemporánea, Buenos Aires, 3: 73-79

- (2000): "It is not all roses here. Ales Hrdlicka's trave$\log$ and his trip to Argentina in 1910". Revista História da Arte e Arqueologia, Campinas 3: 95-105.

Pyenson, L. (1985): Cultural Imperialism and Exact Sciences. German Expansion overseas, 1900-1930. Peter Lang. New York.
Pyenson, L. y Sheets-Pyenson, S. (1999): Servants of Nature. A history of Scientific Institutions, Enterprises and Sensibilities. HarperCollins. Londres.

Quesada, E. (1906): La Facultad de Derecho de París. Estado actual de su enseñanza. Imprenta Coni Hs. Buenos Aires.

- (1910): La enseñanza de la historia en las universidades alemanas. Imprenta Coni Hs. Buenos Aires.

RICHTER, R. (1992): Il bambino straneo. La nascita della imagine dell'infanzia nell mondo borghese. La Nuova Italia. Florencia.

RINGER, F. (1995): El ocaso de los mandarines alemanes. La comunidad académica alemana 1890-1933. Pomares-Corredor. Barcelona.

RoJAs, R. (1909): La restauración nacionalista. Informe sobre educación. Talleres de la Penitenciaría Nacional. Buenos Aires.

Rueda Muñoz de SAn Pedro, G. (1997): "La Sociedad Española de Excursiones. Sus primeros pasos para divulgar la arqueología (1893-1936)". En G. Mora y M. Díaz-Andreu (eds.): La cristalización del pasado: génesis y desarrollo del marco institucional de la arqueología en España. Servicio de Publicaciones de la Universidad. Málaga: 287-293.

SCHNAPP, A. (1996): "French archaeology: between national identity and cultural identity". En M. Díaz-Andreu y T. Champion (eds.): Nationalism and archaeology in Europe. UCL Press. London: 48-67.

Sela, A. (1902): "Las excursiones escolares". Anales de la Universidad de Oviedo, 2: 179-183.

Senet, H. (1891): "Museos escolares. Apuntes sobre la manera de formarlos". Revista de Educación, Buenos Aires, XX, 116: 5-17.

Sheets-Pyenson, S. (1988): Cathedrals of Science. The development of colonial natural history museums in the late nineteenth century. Mc Gill University. Kingston y Montreal.

Trigger, B. (1989): A History of archaeological thought. Cambridge University Press. Cambridge.

Universidad Nacional de La Plata (1910): Digesto. Imprenta Coni. Buenos Aires.

UríA, J. (1994): “La Universidad de Oviedo en el 98. Nacionalismo y regeneracionismo en la crisis finisecular española". En J. Uría González (ed.): Asturias y Cuba en torno al 98. Sociedad, economía, política y cultura en la crisis de entresiglos. Labor. Barcelona: 169-220.

Vitry, P. (1898): “Musées d'enseignement en Allemagne. Musées de moulages antiques et modernes". Revue Internationale de l'Enseignement, 35: 529.

Zubiaur, J. (1897): Excursiones escolares. Establecimiento Tipográfico La Velocidad. Paraná.

T. P., 58, n. ${ }^{\circ} 2,2001$ 